\title{
A STUDY OF KNOWLEDGE, ATTITUDE, AND PRACTICES REGARDING BIOMEDICAL WASTE MANAGEMENT AMONG THE HEALTH CARE WORKERS AT A TERTIARY CARE TEACHING HOSPITAL OF WESTERN UTTAR PRADESH
}

\section{Dr. Abhishek Mehta}

MD (Microbiology), Associate Professor, Govt. Medical College, Datia (MP)

Article Info: Received 22 November 2019; Accepted 17 December 2019

DOI: https://doi.org/10.32553/ijmbs.v3i12.786

Corresponding author: Dr. Abhishek Mehta

Conflict of interest: No conflict of interest.

Place of study: KD Medical College,Hospital \& Research Center, Mathura(UP).

\begin{abstract}
Background: The hazardous impact of biomedical waste on the community and environment is enhanced manifold if it is not managed effectively. Appropriate knowledge and awareness amongst the health care workers about the biomedical waste management, will help in minimizing health care associated infections.

Purpose: There are no such studies in this part of the country to identify the gaps / lacunae in knowledge, attitude \& practices amongst health care workers, so that timely corrective measures could be instituted in the form of educational interventions.

Material \& Methods: This Questionnaire based descriptive study was undertaken at a tertiary care teaching hospital of western Uttar Pradesh in March 2018 after obtaining clearance from Institutional ethics committee. A total of 85 subjects (30 Doctors, 30 Nurses, 25 Laboratory technicians) were administered pre structured pre-validated anonymous questionnaire. Mean scores of the Knowledge, Attitudes and practices of the three groups were compared by Anova test and the comparison between any two study groups done using unpaired t test and the significance level was set to 0.05 .

Results: While comparing Knowledge, attitude and practices between Doctors \& Nurses, though doctors scored higher in all 3 sections but the difference was statistically significant only in the Knowledge and Practice levels. While comparing KAP scores between Nurses \& Lab.technicians, though nurses scored higher but a statistically significant difference was seen in the attitude levels only.There was a statistically significant difference in the scores of Doctors, Nurses \& Lab. Technicians in all the three sections

Conclusion: Such studies help in detecting the gaps \& lacunae in knowledge, attitude \& practices amongst different categories of health care providers which could be addressed through targeted educational interventions at regular intervals. This would help in reducing the incidence of health hazards due to improper BMW management.
\end{abstract}

Keywords: Knowledge, Attitude, Practices, Doctors, Nurses, Laboratory technicians, Questionnaire, Biomedical waste management.

\section{Introduction}

As per Bio-Medical Waste (Management and Handling) Rules, 1998 "Bio-medical waste" (BMW) means any waste, which is generated during the diagnosis, treatment or immunization of human beings or animals or research activities pertaining thereto or in the production or testing of biologicals or in health camps ${ }^{[1]}$.

Existing data derived from a number of studies suggest that $85 \%$ of the waste generated in the hospitals is non-hazardous, $25 \%$ is hazardous out of which only $10 \%$ is infectious which is a potential health hazard to the health care workers and to the environment \& the community at large. As per the record about 0.33 million tons of hospital waste is generated in India and this waste is being generated at the rate ranging from 0.5 to $2 \mathrm{~kg} / \mathrm{bed} /$ day. The hazardous impact of this waste on the community and environment is enhanced manifold if it is not managed effectively. Effective biomedical waste management is not only a legal necessity but also a social, professional and moral responsibility ${ }^{[2,3]}$.

Appropriate knowledge and awareness amongst the health care workers about the biomedical waste management, and proper understanding of the concepts of waste segregation and disposal will help in minimizing health care associated infections. 
In the current global scenario, there is an increasing awareness amongst health care professionals about BMW management but on the contrary a number of studies from various parts of India are pointing towards significant gaps in knowledge and serious lacunae in attitudes and practices being still prevalent amongst different categories of health care providers which is a matter of grave concern ${ }^{[3,4]}$.

There are no such studies in this part of the country and this is need of the hour to explore gaps/lacunae in knowledge, attitude \& practices amongst health care workers, so that timely corrective measures could be instituted in the form of educational interventions/training modules. With this background this Questionnaire based study was undertaken at a rural tertiary care teaching hospital of western Uttarpradesh with the main objective of assessing knowledge, attitude, and practices of health care workers regarding biomedical waste management.

\section{Materials and Method ${ }^{[5,6,7,8,9]}$ :}

This Questionnaire based descriptive study was undertaken at a tertiary care teaching hospital of western Uttarpradesh in March 2018 on 85 Health care workers (HCW) after obtaining clearance from Institutional ethics committee. The purpose and nature of the study was explained to the study participants and only those who volunteered to participate were included in the study, after obtaining informed consent.

A total of 85 subjects (30 Doctors, 30 Nurses, 25 Laboratory technicians) participated in the study. A self administered pre structured pre-validated anonymous questionnaire was administered to each participant. Questionnaire was designed on the basis of relevant literature after extensive literature review and discussion with the subject experts. Questions were checked for their relevance, rationality, clarity and understandability before their final use in the survey.

Questionnaires does'nt reveal any personal identification details of participants and confidentiality was maintained throughout. Questionnaire consisted of a total 30 questions to be answered in 40minutes and divided in four parts:

1) Socio-demographic information (4 questions)

2) Assessment of Knowledge (10 questions)

3) Assessment of Attitudes/Perceptions questions)
4) Assessment of Practices (6 questions)

Knowledge was assessed using 10 questions which included MCQs (Multiple Choice questions).

Attitude was assessed on the basis of 10 questions where the subjects have the choice to opine on a 1 to 5 point Likert scale ranging from Strongly Agree to Strongly Disagree.

Practices were assessed on the basis of 5 questions on a 1 to 5 point Likert scale ranging from Never to Always.

Assessment of Knowledge, attitudes and practices was done on the basis of a scoring system where 1 point was given for each correct response to Knowledge, positive attitude and appropriate practices wherein 0 was given for incorrect knowledge, negative attitude and puny practices. So, the range of KAP score was from 0-25.

Tabulation and compilation of data was done using Microsoft office Excel 2010 software. Appropriate statistical tools were used as per requirement. Pearson's Chi-square test was used to compare the percentages for each of the appropriate responses between the three study groups. p-value of 0.05 was considered as statistically significant.

Mean scores of the Knowledge, Attitudes and practices of the three groups were compared by Anova test and the comparison between any two study groups (Doctors Vs Nurses, Doctors Vs Lab. technicians and Nurses Vs Lab. Technicians) done using paired t test and the significance level was set to 0.05 .

\section{Results:}

The mean age of the participants was $35.4 \mathrm{yrs}$ for doctors, 26.5 yrs. for nurses and 25.8 yrs. for Laboratory technicians. Out of 85 participants, 45 (53\%) were males and 40 (47\%) females. Majority of doctors $(70 \%)$ had received training in Biomedical waste management followed by Nurses (40\%) and Lab.technicians (32\%).

Out of the 10 questions asked in Knowledge section, there was a statistically significant difference in the correct responses by the three groups for the questions pertaining to Definition, Categories, Storage, BMW Rules and Universal precautions while handling BMW.

Most of the participants were able to identify international biohazard sign and knew the hazards 
associated with biomedical waste. Most of the doctors knew the correct definition of biomedical waste and were aware of Universal precautions to be followed while handling biomedical waste. Awareness level regarding biomedical waste rules was very low amongst participants with only $13 \%$ of participants able to answer correctly. Most of the participants were not able to answer the questions pertaining to biomedical waste management, Storage and treatment prior to disposal (Table-1)

Most of the participants while responding to the questions in Attitude section exhibited positive attitude except for the few questions. Statistically significant difference in the responses from the three groups was seen only in one item: "Proper Biomedical waste management is a major issue." In rest of the items the responses from the three groups followed similar pattern. Most of the participants esp. Paramedical staff admitted that they were lacking in the proper knowledge regarding biomedical waste management. Most of the participants from all three groups opined that biomedical waste management increases work burden on employees and financial burden on employers. While $60 \%$ of nurses felt that Safe Biomedical waste management is a team work and not the sole responsibility of hospital authority, $64 \%$ of lab technicians considered it to be the sole responsibility of the Hospital administration (Table-2).

Most of the participants from all three groups through their responses to the concerned items admitted following universal precautions while dealing with BMW and following colour coding system for segregation of BMW at the point of generation. Most of the participants from all three groups admitted that they were not maintaining biomedical waste records properly. Regarding BMW treatment prior to disposal and ensuring proper storage facility, the practice levels was not found to be satisfactory amongst participants (Table-3).

While comparing Mean test scores of Doctors, Nurses \& Lab. Technicians in all the three sections (Knowledge, attitude, Practice), statistically significant difference was seen in the scores in each section (Table-4).

While comparing Knowledge, attitude and practices between Doctors \& Nurses, though doctors scored higher in all 3 sections but the difference was statistically significant only in the Knowledge and Practice levels but not in the attitude levels (Table-5).

Similar observations were recorded while comparing Knowledge, attitude \& practices between Doctors \& Lab. Technicians wherein doctors scored higher but the difference was statistically significant only in the Knowledge and practice levels but not in the attitude levels (Table-6).

While comparing KAP scores between Nurses \& Lab.technicians, though nurses scored higher but a statistically significant difference was seen in the attitude levels only (Table-7).

Table 1: Knowledge of Health care workers regarding Biomedical Waste Management

\begin{tabular}{llllll}
\hline S.No & Question/Item & \multicolumn{4}{l}{ Correct responses n (\%) } \\
\cline { 3 - 5 } & & Doctors (30) & Nurses (30) & Lab. tech. (25) & p-value \\
\hline K1 & Correct definition of BMW & $28(93.33)$ & $23(76.67)$ & $16(64)$ & $0.028^{*}$ \\
\hline K2 & Different categories of BMW & $18(60)$ & $11(36.67)$ & $17(68)$ & $0.049^{*}$ \\
\hline K3 & BMW Rules/regulations 2016 & $7(23.33)$ & $2(6.67)$ & $2(8)$ & $0.044^{*}$ \\
\hline K4 & BMW Management system & $7(23.33)$ & $5(16.67)$ & $5(20)$ & 0.6 \\
\hline K5 & Health hazards associated with BMW & $29(96.67)$ & $26(86.67)$ & $22(88)$ & 0.36 \\
\hline K6 & Colour coding system of bags for BMW segregation & $22(73.33)$ & $19(63.3)$ & $17(68)$ & 0.71 \\
\hline K7 & BMW treatment prior to disposal & $13(43.33)$ & $11(36.67)$ & $6(24)$ & 0.32 \\
\hline K8 & Storage of BMW & $17(56.67)$ & $9(30)$ & $6(24)$ & $0.0253^{*}$ \\
\hline K9 & International Biohazard sign & $30(100)$ & $25(83.3)$ & $24(96)$ & NS $^{*}$ \\
\hline K10 & Universal precautions while handling BMW & $28(93.33)$ & $22(73.3)$ & $15(60)$ & $0.013^{*}$ \\
\hline
\end{tabular}

Significance calculated using Pearson's Chi-square test.

${ }^{*} p<0.05$ (Significant),$\quad \quad \quad * * p<0.001$ (Highly significant),$\quad p>0.05$ (NS: Not significant) 
Table 2: Attitude of Health care workers regarding Biomedical Waste Management

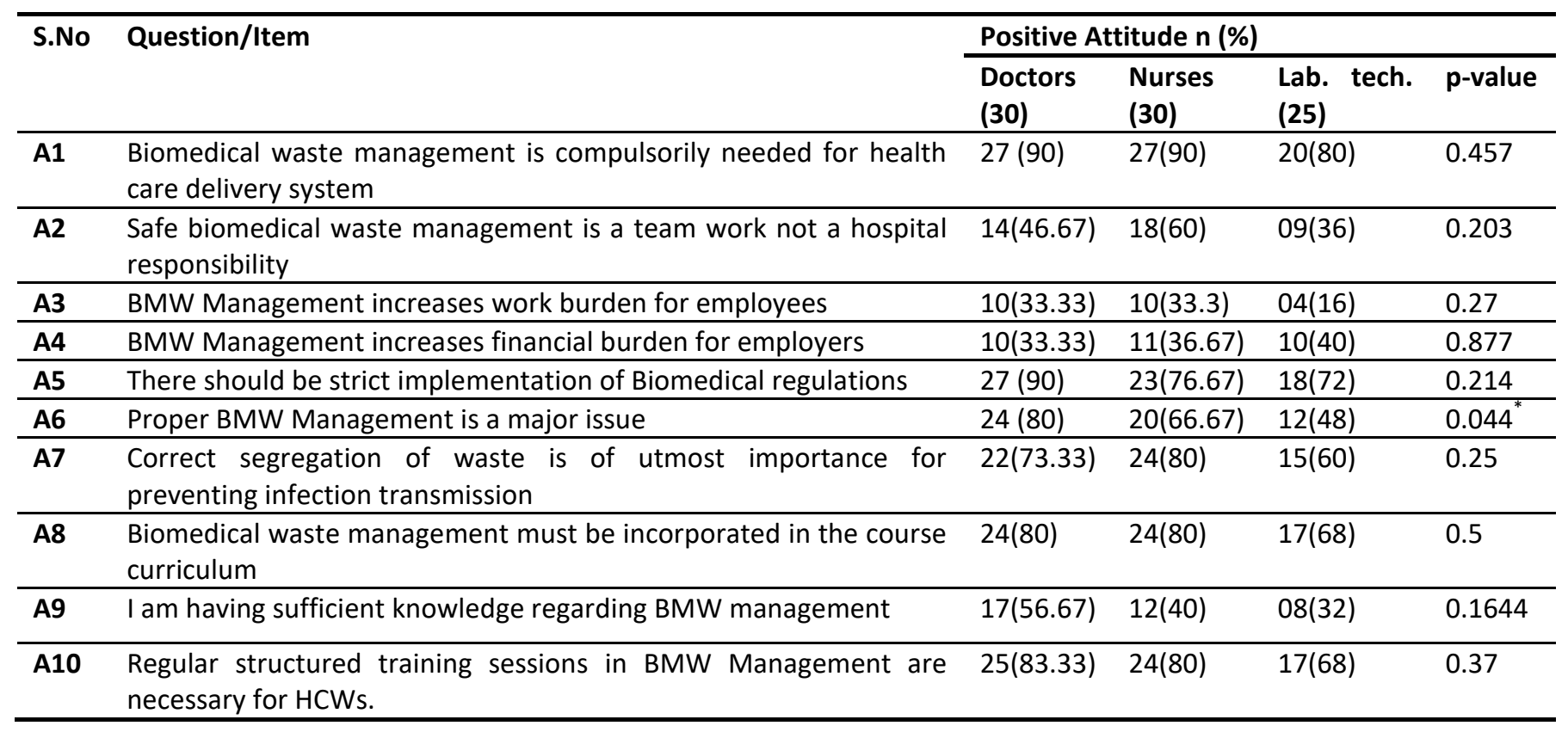

Significance calculated using Pearson's Chi-square test.

$*_{p}<0.05$ (Significant), $\quad * * p<0.001$ (Highly significant) $\quad \quad \quad \quad \quad$ >0.05(NS:Not significant)

Table 3: Practices of Health care workers regarding Biomedical Waste Management

\begin{tabular}{|c|c|c|c|c|c|}
\hline S.No & Question/Item & \multicolumn{4}{|c|}{ Correct Practices n (\%) } \\
\hline $\mathbf{P 2}$ & $\begin{array}{l}\text { Following colour coding system for segregation of BMW at the } \\
\text { point of generation }\end{array}$ & 28(93.33) & $23(76.67)$ & 19(76) & 0.146 \\
\hline P4 & Maintaining BMW Records properly & $14(46.67)$ & $08(26.67)$ & $05(20)$ & 0.3 \\
\hline P5 & Ensuring the provision of proper storage facility for BMW & $21(70)$ & $16(53.33)$ & $12(48)$ & 0.52 \\
\hline P6 & Ensuring that the BMW is being managed as per norms & $19(63.33)$ & 18(60) & $14(56)$ & 0.8 \\
\hline
\end{tabular}

Significance calculated using Pearson's Chi-square test.

${ }^{*} p<0.05$ (Significant),$\quad * * p<0.001$ (Highly significant) $\quad \quad \quad \quad \quad \quad \quad$ >0.05(NS:Not significant)

Table 4: Comparison of Mean KAP Scores of Doctors, Nurses and Laboratory technicians

\begin{tabular}{|c|c|c|c|c|c|}
\hline & \multicolumn{3}{|c|}{ Mean Scores \pm SD } & \multirow[t]{2}{*}{ F-static } & \multirow[t]{2}{*}{ p-value } \\
\hline & Doctors(30) & Nurses(30) & Lab. technicians(25) & & \\
\hline Knowledge & $6.6 \pm 1.75$ & $5.267 \pm 1.98$ & $5.16 \pm 1.67$ & 5.64 & $0.005^{*}$ \\
\hline Attitude & $6.7 \pm 2.184$ & $6.43 \pm 2.22$ & $5.12 \pm 2.22$ & 3.89 & $0.024^{*}$ \\
\hline Practice & $4.2 \pm 1.3$ & $3.467+1.008$ & $3.4+1.12$ & 4.31 & $0.0166^{*}$ \\
\hline
\end{tabular}

Significance calculated using one way Anova test.

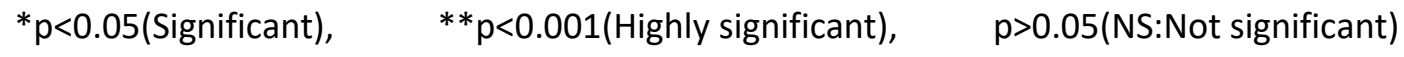


Table 5: Comparison of Knowledge, Attitude \& Practices between Doctors \& Nurses

\begin{tabular}{|c|c|c|c|c|c|}
\hline & \multicolumn{2}{|c|}{ Mean KAP scores \pm SD } & \multirow[t]{2}{*}{ df } & \multirow[t]{2}{*}{ t-value } & \multirow[t]{2}{*}{ p-value } \\
\hline & Doctors & Nurses & & & \\
\hline Knowledge & $6.6 \pm 1.75$ & $5.267 \pm 1.98$ & \multirow{2}{*}{58} & 2.763 & 0.007 \\
\hline Practice & $4.2 \pm 1.3$ & $3.467+1.008$ & & 2.441 & 0.0177 \\
\hline
\end{tabular}

Significance calculated using unpaired t-test.

${ }^{*} p<0.05$ (Significant), $\quad{ }^{* *} p<0.001$ (Highly significant),$\quad p>0.05$ (NS: Not significant)

Table 6: Comparison of Knowledge, Attitude \& Practices between Doctors \& Lab. technicians

\begin{tabular}{|c|c|c|c|c|c|}
\hline & \multicolumn{2}{|c|}{ Mean KAP scores \pm SD } & \multirow[t]{2}{*}{$d f$} & \multirow[t]{2}{*}{ t-value } & \multirow[t]{2}{*}{ p-value } \\
\hline & Doctors(30) & Lab. tech.(25) & & & \\
\hline Knowledge & $6.6 \pm 1.75$ & $5.16 \pm 1.67$ & \multirow{3}{*}{53} & 2.763 & 0.007 \\
\hline Attitude & $6.7 \pm 2.184$ & $5.12 \pm 2.22$ & & 0.475 & 0.6367 \\
\hline Practice & $4.2 \pm 1.3$ & $3.4+1.12$ & & 2.441 & 0.0177 \\
\hline
\end{tabular}

Significance calculated using unpaired t-test.

$*_{\mathrm{p}}<0.05$ (Significant), $\quad * * \mathrm{p}<0.001$ (Highly significant),$\quad \mathrm{p}>0.05$ (NS:Not significant)

Table 7: Comparison of Knowledge, Attitude \& Practices between Nurses \& Lab. technicians

\begin{tabular}{|c|c|c|c|c|c|}
\hline & \multicolumn{2}{|c|}{ Mean KAP scores \pm SD } & \multirow[t]{2}{*}{ df } & \multirow[t]{2}{*}{ t-value } & \multirow[t]{2}{*}{ p-value } \\
\hline & Nurses(30) & Lab.tech.(25) & & & \\
\hline Knowledge & $5.267 \pm 1.98$ & $5.16 \pm 1.67$ & \multirow{3}{*}{53} & 0.214 & 0.83 \\
\hline Attitude & $6.43 \pm 2.22$ & $5.12 \pm 2.22$ & & 2.18 & 0.0338 \\
\hline Practice & $3.467+1.008$ & $3.4+1.12$ & & 0.2334 & 0.8164 \\
\hline
\end{tabular}

Significance calculated using unpaired t-test.

$* \mathrm{p}<0.05$ (Significant) $\quad \quad * * \mathrm{p}<0.001$ (Highly significant),

$p>0.05$ (NS: Not significant)

\section{Discussion:}

In our setup, majority of doctors (70\%) had received training in biomedical waste management followed by Nurses $(40 \%)$ and Lab. technicians (32\%).

The effect of training as well as the educational background of respondents, on the knowledge, attitude \& practices regarding BMW management is clearly evident from our study.

The professionals with higher educational level have better in depth knowledge. This finding is in accordance with the studies conducted by Hakim $\mathrm{S}$ et al 2014, Yadavannavar $M$ et al 2010, Saini et al $2005^{[6,7,8]}$.

The doctors had scored higher than nurses as well as lab. Technicians in all the three sections. This finding is in accordance with the studies conducted by Kumar R et al 2018, Galimany MJ et al 2015, Tenglikar PV et al 2012, Mathur V et al 2011, Kurray et al 2008, Deo D et al 2006, Saini et al $2005^{[8,9,10,11,12,13,14]}$.
So, the doctors can play a key role by motivating the paramedical staff to follow the optimal BMW management practices (Singh A et al 2013) ${ }^{[15]}$.

Mathew SS et al 2011 found that knowledge of the existence of biomedical waste management rules was better among doctors than paramedical staff, but that knowledge of the practical aspects of biomedical waste management was better among paramedical staff $^{[16]}$.

In contrast to it in a study by Sehgal RK et al 2015 the doctors were least exposed to such training programmes though most of the HCWs attended training sessions on BMW management.But the effect of training was more so on the attitude levels of the respondents with the doctors scoring least ${ }^{[17]}$.

In a study by Sachan R et al 2012, doctors had exhibited higher attitude levels than paramedical staff regarding waste collection, segregation and disposal. In similar studies by Madhukumar $S$ et al 2012 and Shafee $M$ et al 2010, nurses exhibited 
better attitude levels than lab.technicians. These findings are in accordance with our study ${ }^{[18,19,20]}$.

A targeted educational intervention not only imparts knowledge increases awareness and keeps them updated about Biomedical waste management but it would also translate in a behavioural change of attitudes and practices to the optimal levels (Suchitra et al 2007) ${ }^{[21]}$.

Assessing the factors affecting compliance to the safe practices provide a chance to address any gaps in knowledge and practices and help in formulating strategy and necessary interventions for minimizing the risk of health hazards like hospital acquired infections or other environmental problems due to improper waste management. HCW if poorly managed may pose risk to health care workers, waste handlers, patients, and the entire community.

Lalita et al. 2011 in her study has shown a need to improve the knowledge about waste management to protect the environment from the negative impact of waste and recommended a need based training program for students and professionals ${ }^{[22]}$.

In a study by Akulume $\mathrm{M}$ et al wherein Azjen's theory of planned behavior (TPB) was applied to prove how the perceived behavioural control through attitude can be translated into practices. Azjens theory is one of the most preferred model for explaining human behaviors but also helps in designing intervention strategies for bringing a change in attitude ${ }^{[23]}$.

A number of studies by Kumar R et al 2018,Tenglikar PV et al 2012, Deo D et al 2006, Saini et al 2005 have reported that the knowledge level of respondents was reflected in their attitudes ${ }^{[8,9,11,14]}$.

A positive correlation between knowledge and practice of the participants as observed in our study means that workers would be able to effectively follow the BMW Management guidelines in their practices if their knowledge level is optimal. This correlation between knowledge and practices regarding BMW management was also reported by Wai et al. 2005 \& Grodzinska et al. $2002^{[24,25]}$

Like other studies(Kumar R et al 2018, Galimany MJ et al 2015, Tenglikar PV et al 2012, Mathur V et al 2011), in our study the nurses, who take up most of the direct patient handling related tasks exhibited lower KAP levels as compared to doctors. It is a matter of concern as they are exposed to the contaminated tissues and items and could be a major source of transmission of hospital-acquired infections $[8,9,10,11,12,13,14]$

In our study most of the participants esp. Paramedical staff admitted that they were lacking in the proper knowledge regarding biomedical waste management. Majority of respondents from all 3 groups opined that BMW management must be incorporated in the course curriculum and structured training sessions in BMW Management should be conducted regularly.

This stresses upon the need for framing written institutional guidelines and designing well structured training modules not only for medicos but also for paramedics who are the direct heath care providers [21].

One of the important limitations of this study is the practice assessment by using self administered questionnaires. Although self-reporting may be the simplest, easiest way and less time consuming but it always carries a risk of respondent bias who will try to report better practice than what is actually done.

Declared practices may or may not reflect actual practices - only direct observation can confirm improvement of actual practices. So, further studies are suggested involving Checklist based onsite assessment through direct observation to analyse the impact of educational interventions on the actual practices of the study subjects. Further small sample size in the study makes it difficult to generalize the findings.

Inspite of these limitations, this study is still a good starting point for more extensive research in near future with the broad aim of improving our health care delivery system.

Further studies on larger scale should be conducted to detect the gaps and lacunae in the Knowledge, attitude and practice levels and to find out the causative factors behind this and how these could be addressed for the overall improvement in BMW management practices.

So, it was suggested that intensive training sessions has to be conducted regularly for all health care providers including sanitary staff which will help in better retention of knowledge and instilling a positive attitude towards biomedical waste management by repetitive reinforcement. It would also translate in a behavioural change of attitudes and practices that 
would help in reducing the incidence of health hazards due to improper BMW management.

\section{References:}

1. Ministry of Environment and Forests, Government of India. Notification on the Bio-Medical Waste (Management and Handling) Rules. New Delhi, India:Gazette notification No 460 dated July27, New Delhi: 1998:10-20.

2. Kusuma ML, Ranjini N, Anitha KT, Khan MA, Ahmed M. Biomedical Waste Management: An Interventional Study among Nursing Staff in Teritiary Care Hospital of Mysore. Journal of Evolution of Medical and Dental Sciences 2015; 4(8): 15017-15023.DOI: 10.14260/ jemds/2015/2131

3. Dudi M, Sharma R, Sharma S, Jain M. Assessment of the knowledge, attitude and practices regarding Biomedical Waste Management amongst Paramedical Staff in a Tertiary Level Health Care Facility. Int J Med Sci Public Health 2016;5:615-619.

4. Karmakar N, Datta SS, Datta A, Nag K, Tripura K, Bhattacharjee P.Cross-sectional study on knowledge, attitude and practice of biomedical waste management by health care personnel in a tertiary care hospital of Agartala, Tripura. National Journal of Research in Community Medicine 2016; 5(3): 189 195.

5. Mehta A, Tripathi K. Knowledge, attitude and practices of hand hygiene among nurses and nursing students in a tertiary health care center of central India: a questionnaire based study. Int J Community Med Public Health 2019 ; 6: 5154-60.

6. Hakim SA, Mohsen A, Bakr I.Knowledge, attitudes and practices of health-care personnel towards waste disposal management atAin Shams University Hospitals, Cairo. Eastern Mediterranean Health Journal 2014; 20(5): 347-354

7. Yadavannavar $M$, Berad AS, Jagirdar P. Biomedical waste management: a study of knowledge, attitude, and practices in a tertiary health care institution in Bijapur. Indian Journal of Community Medicine, 2010, 35:170-171.

8. Saini S, Nagarajan SS, Sarma RK. Knowledge, attitude and practices of biomedical waste management amongst staff of a tertiary level hospital in India. Journal of the Academy of Hospital Administration India, 2005, 17:1-12.

9. Kumar R, Somrongthong R, Ahmed J, Almarabheh AJ. Correlates of Knowledge, Attitude and Practices about Health Care Waste Management among Hospital Workers of Pakistan. J Liaquat Uni Med Health Sci. 2018; 17 (01): 01-7. doi: 10.22442/jlumhs.181710541

10. Galimany MJ, Torres EP, Sancho AR, Girbau GMR, Fabrellas N, Torrens GML, et al. Management of Healthcare Waste in the Hospital Setting.
Understanding Risk Management. Rev Enferm. 2015; 38(5):14-9.

11. Tenglikar PV, Kumar AG, Kapate R, Reddy S, Vijayanath V. Knowledge Attitude and Practices of Health Care Waste Management amongst Staff of Nursing Homes of Gulbarga City. Journal of Pharmaceutical and Biomedical Sciences 2012; 19(19) :1-3.

12. Mathur V, Dwivedi S, Hassan MA, Misra RP. Knowledge, Attitude, and Practices about Biomedical Waste Management among Healthcare Personnel: A Cross-sectional Study. Indian J Community Med. 2 011; 36(2):143-5

13. Kurray et al.Knowledge, Attitude and Practices related to Hospital waste management amongst the Resident doctors, Nursing staff and Class IV employees in a tertiary level hospital in Mumbai. PRESM Journal of Community Medicine 2008; 10:1-3.

14. Deo D, Tak SB, Munde SS. A Study of Knowledge Regarding Biomedical Waste Management among Employees of a Teaching Hospital in Rural Area. Journal of ISHWM 2006 ; 5(1): 12-5.

15. Singh A, Srivastava RN. Knowledge, attitude and practices of bio-medical waste management amongst staff of institutional trauma center level II. International Journal of Research in Health Sciences. 2013; 1: 262-68.

16. Mathew SS, Benjamin Al, Sengupta P. Assessment of biomedical waste management practices in a tertiary care teaching hospital in Ludhiana. Healthline 2011, 2:28-30.

17. Sehgal RK, Garg R, Dhot PS, Singhal P. A study of knowledge, attitude, and practices regarding biomedical waste management among the healthcare workers in a multispeciality teaching hospital at Delhi. Int J Med Sci Public Health 2015;4:1540-1544.

18. Sachan R, Patel ML, Nischal A. Assessment of the knowledge, attitude and practices regarding biomedical waste management amongst the medical and paramedical staff in tertiary health care centre. International Journal of Scientific and Research Publications 2012; 2(7):1-6.

19. Madhukumar S, Ramesh G. Study about awareness and practices about health care waste management among hospital staff in a medical college hospital, Bangalore. Iranian Journal of Basic Medical Sciences 2012; 3:7-11.

20. Shafee $M$, Kasturwar N, Nirupama N. Study of knowledge, attitude and practices regarding biomedical waste among paramedical workers. Indian Journal of Community Medicine 2010; 35:369-370.

21. Suchitra JB, Lakshmi Devi N. Impact of education on knowledge, attitudes and practices among various categories of health care workers on nosocomial infections. Indian J Med Microbiol. 2007 ;25(3):181-7

22. Lalita Arora, Sunita Agarwal. Knowledge, attitude and practices regarding waste management in selected 
hospital students of university of Rajasthan, Jaipur. International J of Chemical, Environmental and Pharmaceutical Research 2011; 2(1): 40-43.

23. Akulume M, Kiwanuka SN. Health Care Waste Segregation Behavior among Health Workers in Uganda: An Application of the Theory of Planned
Behavior. Journal of Environmental and Public Health 2016;16: 1-8. https://doi.org/10.1155/2016/8132306.

24. Wai S,Tantrakarnapa K., Huangprasert S. Thai environmental Engineering Journal 2005; 19 (2) : 1619.

25. Grodzinska-Jurczak M.S, Friedlein K.Environmental Science and Pollution Res. 2002; 3 (3) : 210-215. 